\title{
PRÉ-DIMENSIONAMENTO DE UM TERMINAL RODOVIÁRIO PARA A CIDADE DE
}

\section{CAÇADOR - SC}

PRE-DIMENSION OF AN BUS TERMINAL FOR THE CITY OF CAÇADOR - SC

Francieli Piran ${ }^{1}$

Gabriela Cassol ${ }^{2}$

Marcelo Wandscheer ${ }^{3}$

\section{RESUMO}

Este artigo trata a respeito do pré-dimensionamento de um novo terminal rodoviário para a cidade de Caçador - SC. A presente pesquisa tem como objetivo geral a elaboração do pré-dimensionamento, o qual deverá contribuir significativamente para a melhoria do serviço de viação rodoviária no município diminuindo o fluxo de trânsito na zona central. A metodologia adotada nesta monografia foi por meio de referencial bibliográfico, estudo preliminar, levantamento de dados, programa de necessidades, pré-dimensionamento e montagem do funcionograma. Como resultados, obteve-se uma consulta de viabilidade na prefeitura do munícipio de Caçador - SC, a partir do qual foi realizada a escolha do local da edificação, bem como uma pesquisa em uma das empresas que atuam no terminal, apresentando a situação atual do terminal, para finalmente através desses parâmetros realizar o pré-dimensionamento necessário. Palavras-Chave: Pré-dimensionamento. Terminal rodoviário. Programa de necessidades. Funcionograma.

\footnotetext{
${ }^{1}$ Acadêmica do Curso de Engenharia Civil da Universidade Alto Vale do Rio do Peixe (UNIARP). Email: francieli_piran@hotmail.com.

2 Professora Orientadora. Graduado em Engenharia Civil, pela Universidade do Oeste de Santa Catarina (UNOESC), Mestre em Engenharia Civil pela Universidade Estadual Paulista (UNESP), e docente do Curso de Engenharia Civil da Universidade Alto Vale do Rio do Peixe. Email: gabriela.cassol@uniarp.edu.br.

3 Professor Coorientador. Graduado em Arquitetura e Urbanismo, pela Universidade Federal de Santa Catarina (UFSC), Especialista em Administração, Gestão Pública e Politicas Sociais pela Faculdade Dom Bosco, FDB, Brasil. e docente do Curso de Engenharia Civil e de Arquitetura e Urbanismo da Universidade Alto Vale do Rio do Peixe. Email: mwan1818@gmail.com.
} 


\section{ABSTRACT}

This article deals with the pre-dimensioning of a new bus terminal for a city of Caçador - SC. The present research has as general objective the elaboration of the pre-dimensioning, which is a significant contribution to an improvement of the highway road service in the city, reducing the flow of traffic in the central zone. The methodology adopted in a monograph was by means of a bibliographic reference, preliminary study, data collection, needs program, pre-dimensioning and assembly of the program. As a result, a feasibility study was carried out at the municipality of Caçador - SC, from which a choice was made of the building site, such as a research in a company that operates in the terminal, presenting a current Terminal situation, To finally achieve these standards perform the necessary pre-sizing.

Keywords: Preliminary design. Bus Station. Needs program. Diagram.

\section{INTRODUÇÃO}

No mundo globalizado, onde o acesso à informação e produtos têm se tornado cada vez mais simplificado, chegam até nós dados alarmantes, aquecimento global, poluição, população aumentando, falta de água, escassez de alimentos, epidemias e pandemias, bactérias resistentes, entre tantos outros problemas que se agravam a cada dia.

Com essas informações nos voltamos ao nosso Brasil, onde de tantos problemas que observamos, damos destaque ao trânsito. Um dos vilões dos dias atuais, responsável por um dos maiores índices de mortalidades dos brasileiros.

Santa Catarina tem o maior índice nacional de automóveis por habitante, alcançando um expressivo número de 0,54 automóveis/habitante (OLENIKE ET al., 2011). Neste caso, suponhamos que um ônibus leve em média 30 passageiros, seriam necessários seis automóveis para substituí-lo, ou seja, seis automóveis a mais no trânsito. Assim, observamos a necessidade e importância dos transportes rodoviários de passageiros em nosso meio.

Com isso, surge a necessidade de pesquisar, analisar e obter referências para a concepção de um pré-dimensionamento para a implantação de um novo terminal rodoviário para a cidade de Caçador - SC.

O presente trabalho justifica-se, pois o terminal rodoviário do município de Caçador - SC encontra-se defasado, não atendendo a demanda atual de ônibus 
e também o conforto dos usuários. Com isso, pretende-se através deste trabalho ampliar a utilização do transporte rodoviário de passageiros, sugerir uma nova estrutura ao terminal rodoviário do município, proporcionando maior conforto aos usuários enquanto aguardam o embarque no ônibus e aliado a isso proporcionar maior fluidez ao trânsito no entorno do atual terminal, redirecionando o fluxo de ônibus para as rodovias, removendo o mesmo do centro da cidade.

O objetivo geral deste trabalho é o pré-dimensionamento de um novo terminal intermunicipal rodoviário de passageiros para o município de Caçador SC, o qual deverá contribuir significativamente para a melhoria do serviço de viação rodoviária em nosso município, para a diminuição do fluxo de trânsito na zona central.

Os objetivos específicos são: determinar a localização do novo terminal rodoviário, realizar o estudo preliminar, o programa de necessidades e o funcionograma.

\section{DESENVOLVIMENTO}

\section{REFERENCIAL TEÓRICO}

\section{Terminal Rodoviário de Passageiros (TRP)}

O TRP é o ponto de chegada e saída dos usuários, principalmente os de média e longa distância, ou seja, a conexão entre o passageiro, o sistema e as cidades (SOARES, 2006).

Para Maas (2001 apud FERREIRA; FANTIN, 2010) um terminal não atende somente passageiros, mas tambem entrada e saída de cargas de um sistema de tranporte.

Ainda, segundo Soares (2006) um terminal pode ser conceituado como qualquer ponto a fim de realizarem-se embarques ou desembarques de passageiros num sistema de transporte. 


\section{Características do terminal rodoviário de passageiros}

Para Soares (2006), as características básicas de um TRP são:

a) Áreas de circulação: consistem em alas internas atribuídas à circulação de todos os usuários; portais de entrada e saída para uso do público; e também serviços institucionais de fiscalização e policiamento, bem como ambulatório de socorro emergencial;

b) Alas internas: destinadas aos boxes dos transportes rodoviários; venda de bilhetes de viagem; lojas de conveniência; praças de alimentação; e outras comodidades;

c) Terminais de embarque e desembarque: compreendem os corredores e portões de acesso; bem como pistas internas com plataformas atribuídas para baias de estacionamento de ônibus rodoviário;

d) Instalações administrativas e operacionais do equipamento e das áreas de estacionamento exclusivas da administração e para o público.

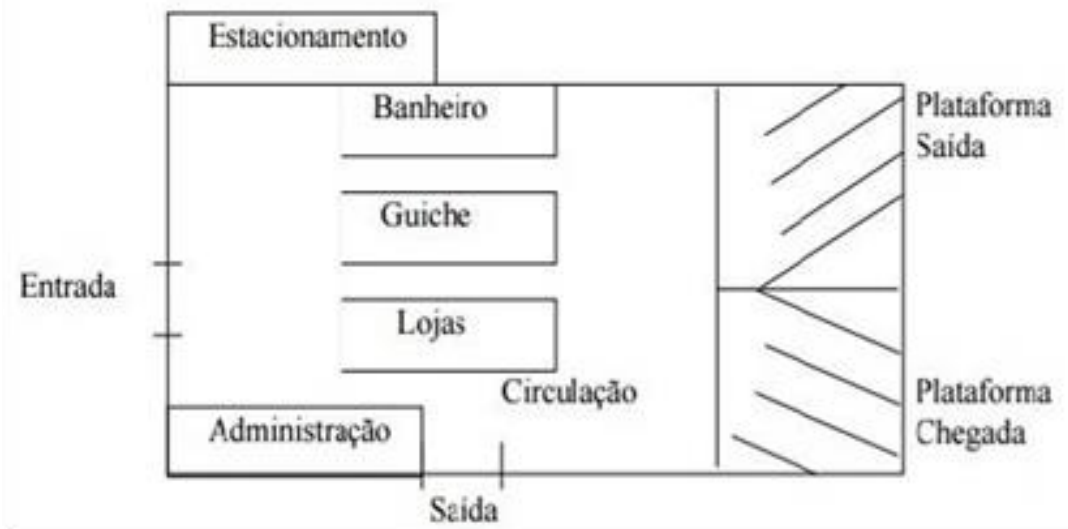

Figura 1 - Elementos principais de um terminal

Fonte: Dunham (2008)

\section{Classificação dos terminais rodoviários de passageiros}

Gouvêa (1980 apud SOARES, 2006), apresenta uma classificação conforme o modo de transporte e à organização política-administrativa.

Referente ao modo de transporte:

a) Terminal unimodal: é o terminal que oferece serviços exclusivamente a um único modo de transporte, como exemplo temos as estações 
ferroviárias e paradas de ônibus;

b) Terminal multimodal: presta serviços a mais de um modo de transporte, normalmente com um ponto de transbordo. Esse terminal é referência em grandes cidades.

Com relação à organização política-administrativa:

a) Terminal urbano: terminais onde o ponto extremo da viagem se encontra na mesma cidade, tendo dependência socioeconômica, onde os passageiros são evidenciados por ausência de bagagens e geralmente viagens diárias. Encontra-se em regiões metropolitanas;

b) Terminal interurbano: é onde o ponto de chegada e partida encontra-se em cidades diferentes, com independência socioeconômica. Capazes de prestar serviços de transporte de médias e longas distâncias.

\section{Localização dos terminais rodoviários de passageiros}

O local deve ser escolhido levando em consideração a disponibilidade da área, onde devem ser levados em conta os impactos ambientais e áreas para expansão do terminal; a acessibilidade, onde deve ser de fácil acesso às regiões de maior tráfego; aos serviços públicos disponíveis, como rede de água, esgoto, energia elétrica, telefonia e custos de implantação, os custos de projeto e construção e avaliação de impactos ambientais (FERREIRA; FANTIN, 2010).

Ainda segundo os autores, aspectos negativos como poluição do ar, da água, poluição sonora, visual, aumento de tráfego, dificuldade para o deslocamento de pessoas, prejuízos ao desenvolvimento urbano, devem ser analisados, mantendo a acessibilidade para todos os usuários, do contrário, a busca pelos serviços pode ser diminuída consideravelmente.

Para Gouvêa (1980 apud SOARES, 2006), a localização dos terminais não deve prejudicar seus usuários nem o seu entorno. Tempos de viagens ampliados, maior deslocamento por parte de veículos e pedestres, tráfego adicional às vias precárias, devem ser evitados, facilitando assim o dia-a-dia de ambos. 


\section{METODOLOGIA E MATERIAL}

\section{PARÂMETROS DE OCUPAÇÃO E USO DO SOLO URBANO}

Para encontrar os parâmetros de ocupação e uso do solo urbano da cidade de Caçador - SC foi realizada uma consulta de viabilidade na prefeitura municipal da cidade.

\section{ESCOLHA DO LOCAL DA EDIFICAÇÃO}

Para a determinação da escolha do local onde foi executado o projeto foram priorizados alguns aspectos como:
a) Acessibilidade ao local;
b) Descentralização;
c) Ganho no tempo de viagem em um contexto urbano;
d) Local favorável em um ponto de vista sustentável.

\section{ESTUDO PRELIMINAR}

O presente trabalho foi desenvolvido baseando-se em pesquisas bibliográficas, incluindo livros, dissertações, normas e sites. O trabalho seguiu da seguinte maneira:
a) Pesquisa bibliográfica;
b) Definição do local do terreno;
c) Realização do programa de necessidades;
d) Estudo e concepção do pré-dimensionamento;
e) Análise final e conclusões.

\section{LEVANTAMENTO DE DADOS}

Para o levantamento de dados foi realizado uma pesquisa na empresa Reunidas S.A. Transportes Coletivos juntamente com informações levantadas na Rodoviária Municipal de Caçador, enfatizando a demanda de ônibus e o número de passageiros diário, cidades atendidas e o número de empresas que prestam serviço 
ao terminal.

PROGRAMA DE NECESSIDADES

Segundo Karlen (2010), define-se programa de necessidades como documentos escritos que podem classificar e quantificar as necessidades do cliente e/ou usuário do projeto. Para obter um programa de necessidades completo, deve ser realizado entrevistas, observações em campo, estabelecer os parâmetros de arquitetura, organizar os dados coletados, estudar as variáveis de projeto, analisar, interpretar e colocar os dados em um diagrama e por fim sintetizá-los para o projeto.

PRÉ DIMENSIONAMENTO

Para Neves (2012), o pré-dimensionamento é o dimensionamento prévio do projeto, em aspecto bidimensional, ou seja, relativo à área. Há a necessidade de calcular as áreas de cada elemento a ser utilizada no projeto, as quais servirão para o funcionamento do mesmo. Por se tratar de um dimensionamento prévio, essas áreas podem ser alteradas posteriormente, não ultrapassando uma margem de $10 \%$ ao decorrer do processo. O pré-dimensionamento deve estar em comum acordo com o programa de necessidades bem como as atividades que serão desenvolvidas no edifício.

\section{MONTAGEM DO DIAGRAMA/FUNCIONOGRAMA}

O funcionograma refere-se ao diagrama de relações funcionais dos elementos de um programa, ou seja, liga os elementos pelo grau de afinidade que possuem entre si, como por exemplo, a ligação entre quartos e banheiro, constituindo um setor íntimo. É necessário deixar claro, que o funcionograma diz respeito apenas à ligação entre os elementos do programa, não expressando nada relacionado à conexão entre os componentes do projeto, nem a posição do elemento no terreno, nem a distância entre os cômodos. Essa ligação entre os componentes pode ser interpretada de forma incorreta, podendo ser um hall, uma porta ligando dois ambientes, um corredor, uma escada, uma rampa, um elevador, etc. (NEVES, 2012). 


\section{RESULTADOS E DISCUSSÕES}

\section{ESCOLHA DO LOCAL DA EDIFICAÇÃO}

O terreno escolhido para a implantação do projeto encontra-se às margens da rodovia Honorino Moro e ao lado da Rua Benjamin Gioppo.

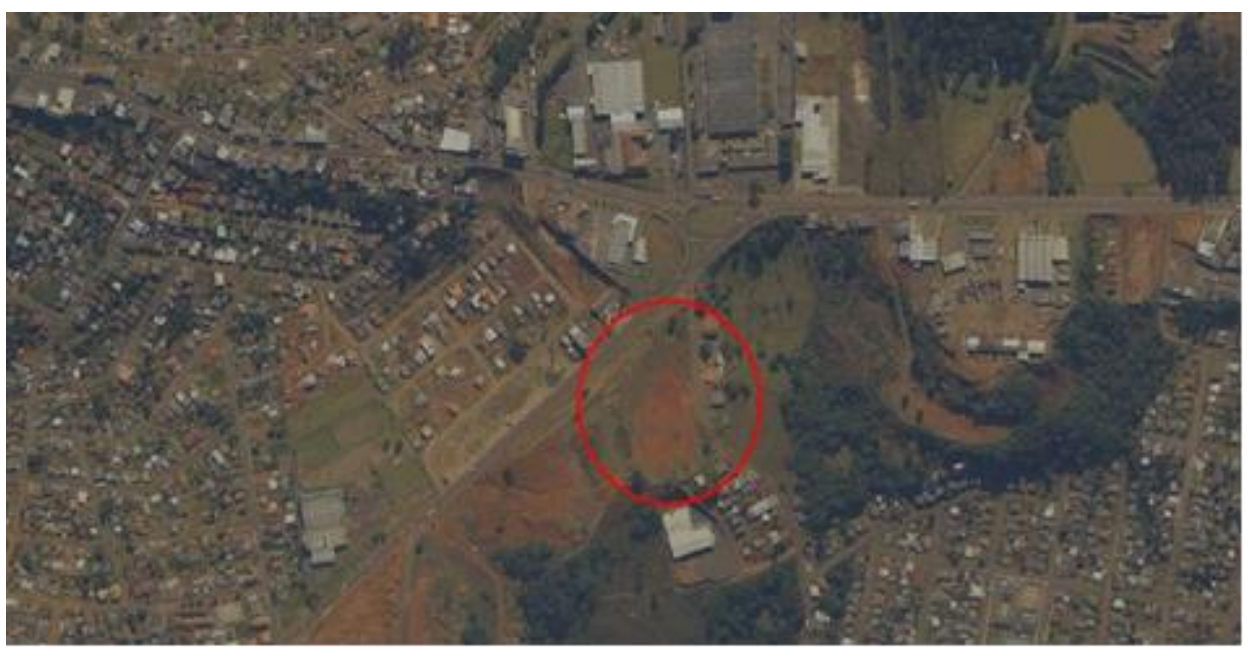

Figura 02 - Imagem do terreno a ser implantado o projeto

Fonte: SIGSC (2012)

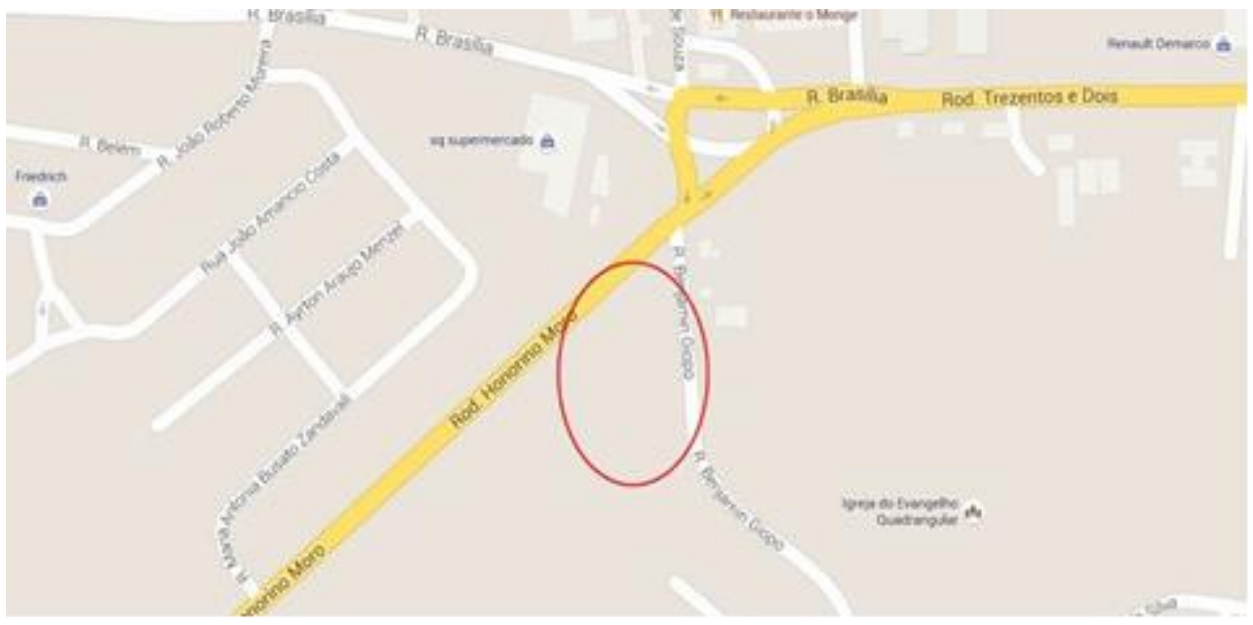

Figura 03 - Mapa do terreno a ser implantado o projeto Fonte: Google Maps (2016)

Para o terreno escolhido como local da edificação foi pré-determinado uma área de construção de 10.000,00 m². 


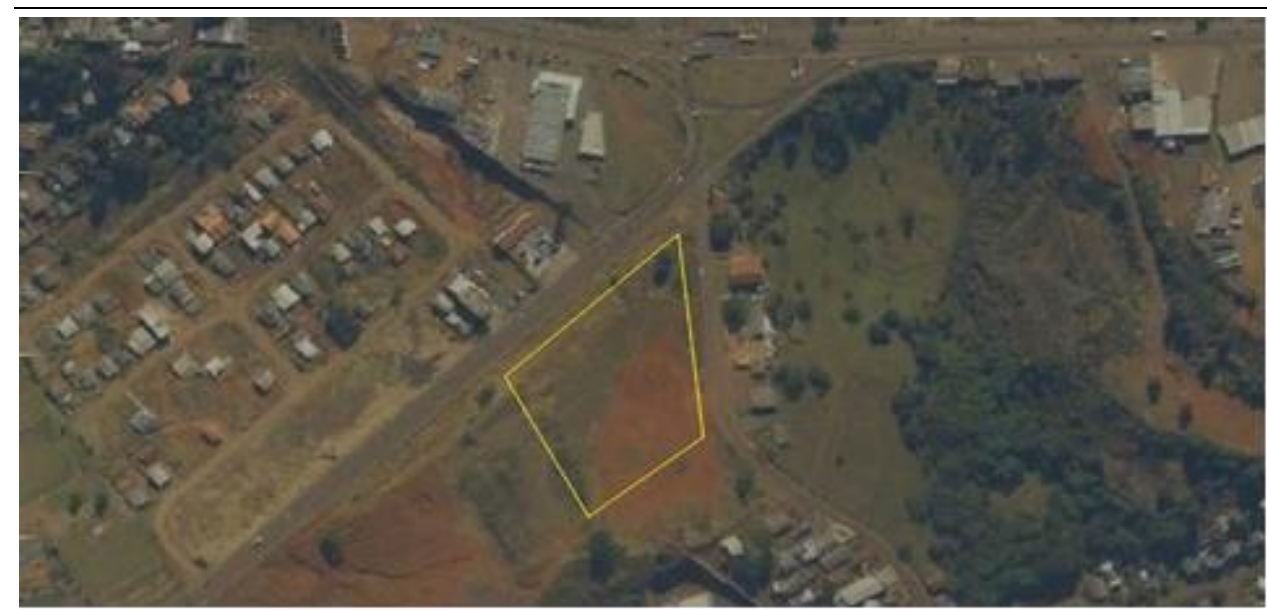

Figura 4 - Imagem do terreno com área de construção pré-determinada.

Fonte: SIGSC (2016)

O futuro terminal se localiza na zona ZS (Zona de Serviço).

Zona de Serviços - ZS: compreende as áreas ao longo de eixos rodoviários ou grandes eixos viários, destinadas à implantação de atividades comerciais e de serviços que, por seu porte ou natureza, exijam confinamento em áreas próprias ou sejam geradoras de tráfego pesado ou intenso (LEI COMPLEMENTAR № 168, 2010, p.05);

Segundo a Lei Complementar № 168, de 16 de abril de 2010 (Lei de Zoneamento do município de Caçador - SC) a zona ZS (Zona de Serviço) são permitidos as atividades de Habitação Unifamiliar (HU), e atividades do grupo 1 (Não Geradores de Incômodo - são os usos que não apresentam caráter de incomodidade, neles se incluindo a atividade residencial unifamiliar), 2 (Compatíveis - são os usos que são compatíveis com a zona urbanística e por seu nível de incomodidade, porte, periculosidade, potencial poluidor, potencial gerador de tráfego e incremento da demanda por infraestrutura, podem e devem integrarse à vida urbana, adequando-se a padrões comuns de funcionamento, estabelecidos pelo Código de Posturas e aprovados pelos órgãos competentes), 3 (Geradores de Incômodo - são os usos que, por seu nível de incomodidade, porte, periculosidade, potencial poluidor, potencial gerador de tráfego e incremento da demanda por infraestrutura, podem integrar-se à vida urbana comum, adequandose às exigências do Código de Posturas, mas que precisam de análise especial para verificar a possibilidade de convivência com o uso residencial) e 4a (Geradores de Impacto - Compatível: abrangem as atividades e empreendimentos, que apesar de 
seu caráter altamente impactante não podem afastar-se do meio urbano comum) e permissível às atividades do grupo $4 b$ (Geradores de Impacto - Não Compatível: abrangem as atividades e empreendimentos altamente impactantes que precisam ser afastados do meio urbano comum, localizando-se na Zona Industrial) e Habitação Multifamiliar Vertical (HMV).

Através da consulta de viabilidade realizada na prefeitura municipal de Caçador - SC, obtive os parâmetros construtivos do terreno escolhido. O coeficiente de aproveitamento básico resultou em 1, assim como o máximo, e o mínimo 0,15. A taxa máxima de ocupação ficou em 60\%, e a taxa de permeabilidade mínima 25\%. A altura máxima é até 3 pavimentos mas com base em estudos de ocupação específica, poderão ser aprovadas alturas maiores, a critério da Comissão Técnica de Urbanismo - CTU e aprovadas pelo IPPUC. O recuo frontal resultou em 5 metros e deve-se respeitar a faixa de domínio e faixa não edificante da rodovia. O afastamento lateral e de fundos ficou em 2 metros e o lote mínimo $15 \mathrm{~m} \times 450 \mathrm{~m}^{2}$.

Segundo a Lei Complementar № 168, de 16 de abril de 2010 (Lei de Zoneamento do município de Caçador - SC) as exigências mínimas de vagas de estacionamento para terminais rodoviários é de 1 a cada 80 metros quadrados de área instalada, sendo que cada vaga será calculada com 12,5 metros quadrados.

ESTUDO PRELIMINAR

\section{Levantamento de dados}

Foi realizada uma pesquisa na empresa Reunidas S.A. Transportes Coletivos juntamente com informações coletadas na Rodoviária Municipal de Caçador, com os seguintes dados:

a) Número de empresas que prestam serviços ao terminal:

No atual terminal rodoviário de passageiros do município de Caçador são quatro empresas que prestam serviços, sendo a Reunidas, Unesul, Planalto e Catarinense.

b) Demanda diária de ônibus:

Diariamente, são em média trinta e três ônibus que passam pelo terminal. 


\section{c) Cidades atendidas}

Saindo do terminal rodoviário do município de caçador, pode-se ir a 90 (noventa) cidades diferentes.

d) Demanda diária de passageiros:

Os dados a seguir, foram coletados da empresa Reunidas S.A. Transportes Coletivos referentes ao número de passagens vendidas no ano de 2015:

Tabela 01 - Número de passagens comercializadas pela empresa Reunidas no ano de 2015

\begin{tabular}{cc}
\hline Mês & Número de passagens vendidas: \\
\hline Janeiro & 7592 \\
Fevereiro & 6362 \\
Março & 7129 \\
Abril & 7126 \\
Maio & 6490 \\
Junho & 5835 \\
Julho & 6601 \\
Agosto & 5850 \\
Setembro & 5674 \\
Outubro & 6558 \\
Novembro & 4539 \\
Dezembro & 6811 \\
Total & 76567 \\
\hline
\end{tabular}

Fonte: O próprio autor.

Foram comercializadas pela empresa Reunidas no total 76.567 passagens no ano de 2015, resultando em uma média mensal de 6.381 passageiros.

\section{Atual terminal rodoviário}

O atual Terminal Rodoviário da cidade de Caçador encontra-se no centro da cidade, anexo ao Parque Central José Rossi Adami, contornada pelas ruas Luiz Caramori e Aristeu Porto Lopes. 


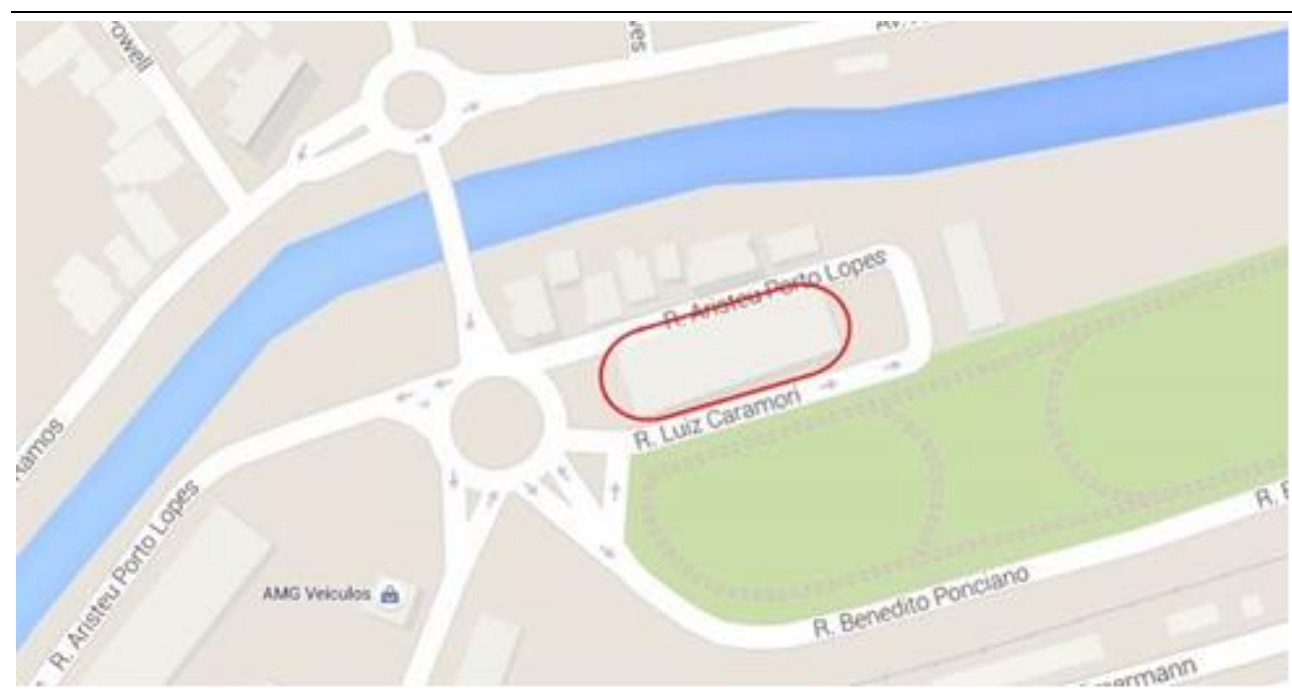

Figura 05 - Mapa da atual rodoviária de Caçador-SC

Fonte: Google Maps (2016)

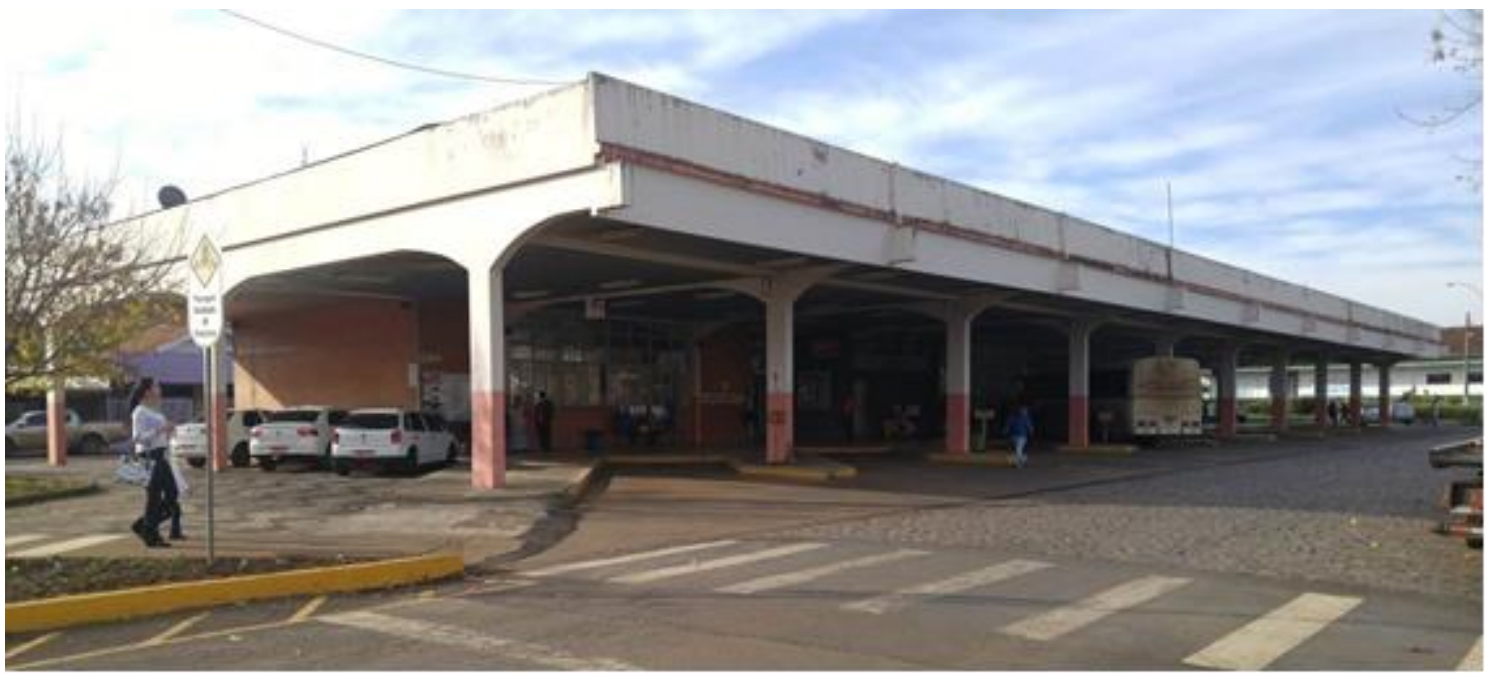

Figura 06 - Imagem da atual rodoviária de Caçador-SC

Fonte: O próprio autor.

Sua situação está bastante precária, além de inviável no ponto de vista urbanístico e sustentável. Seu estado de conservação está debilitado e não atende as normas de acessibilidade.

PROGRAMA DE NECESSIDADES

Realizou-se o pré-dimensionamento de um novo terminal rodoviário de 
passageiros intermunicipal para o município de Caçador, com a finalidade de comercialização de passagens, servir de ponto de embarque e desembarque de passageiros, além de atender as necessidades dos clientes.

Pensando nisso, o projeto conta com setor de operação que são destinadas às atividades de venda de passagens, administração, espera, chegada e saída dos ônibus e embarque e desembarque de passageiros. O setor de serviços públicos que destina-se às atividades de apoio, assistência e proteção aos usuários do terminal. O setor de uso público, onde refere-se ao atendimentos dos usuários em geral. O setor de comércio que são aquelas destinadas às atividades de venda de bens aos usuários e outras. E o setor administrativo, destinado à área administradora do terminal, exercendo suas atividades pertinentes.

A Tabela 02 apresenta o programa de necessidades inicial com as características das instalações.

Tabela 02 - Características das instalações

\begin{tabular}{|c|c|c|c|}
\hline Instalação & Função & Mobiliário & Necessidades especiais \\
\hline Administração & $\begin{array}{l}\text { Administrar o } \\
\text { terminal }\end{array}$ & $\begin{array}{l}\text { Mesas, cadeiras, } \\
\text { computadores, } \\
\text { arquivos }\end{array}$ & Iluminação natural \\
\hline Bilheterias & $\begin{array}{l}\text { Venda de } \\
\text { passagens }\end{array}$ & $\begin{array}{c}\text { Mesas, cadeiras e } \\
\text { equipamento } \\
\text { necessários }\end{array}$ & $\begin{array}{c}\text { Acessibilidade, localizado } \\
\text { próximo a área de } \\
\text { embarque/desembarque }\end{array}$ \\
\hline Comércios & $\begin{array}{l}\text { Atender o público } \\
\text { em geral }\end{array}$ & $\begin{array}{c}\text { Balcões, expositores } \\
\text { e equipamentos } \\
\text { necessários }\end{array}$ & $\begin{array}{c}\text { Acessibilidade, iluminação } \\
\text { natural }\end{array}$ \\
\hline Depósitos & $\begin{array}{l}\text { Armazenar } \\
\text { materiais }\end{array}$ & $\begin{array}{l}\text { Prateleiras e } \\
\text { equipamentos } \\
\text { necessários }\end{array}$ & - \\
\hline Vestiário & $\begin{array}{l}\text { Troca de roupas de } \\
\text { funcionários }\end{array}$ & $\begin{array}{c}\text { Prateleiras, cabides e } \\
\text { equipamentos } \\
\text { necessários }\end{array}$ & - \\
\hline Sanitários & $\begin{array}{c}\text { Atender as } \\
\text { necessidades } \\
\text { fisiológicas }\end{array}$ & $\begin{array}{l}\text { Vaso sanitário, } \\
\text { lavatório e mictório }\end{array}$ & Acessibilidade \\
\hline Achados e perdidos & $\begin{array}{l}\text { Armazenar } \\
\text { achados e } \\
\text { perdidos }\end{array}$ & $\begin{array}{c}\text { Mesa, cadeira, } \\
\text { prateleiras e cabides }\end{array}$ & $\begin{array}{c}\text { Fácil acesso e visibilidade, } \\
\text { iluminação natural, } \\
\text { acessibilidade }\end{array}$ \\
\hline Guarda volumes & $\begin{array}{c}\text { Guardar } \\
\text { temporariamente } \\
\text { materiais }\end{array}$ & $\begin{array}{c}\text { Mesa, cadeira, } \\
\text { prateleiras, cofres }\end{array}$ & $\begin{array}{c}\text { Fácil acesso e visibilidade, } \\
\text { iluminação natural, } \\
\text { acessibilidade }\end{array}$ \\
\hline Juizado de menores & $\begin{array}{l}\text { Prezar sobre os } \\
\text { direitos dos } \\
\text { menores }\end{array}$ & $\begin{array}{l}\text { Mesa, cadeiras, } \\
\text { computadores }\end{array}$ & $\begin{array}{c}\text { Acessibilidade, localizado } \\
\text { próximo a área de } \\
\text { embarque/desembarque }\end{array}$ \\
\hline
\end{tabular}




\begin{tabular}{cccc}
\hline $\begin{array}{c}\text { Guarda } \\
\text { municipal/Policiamento }\end{array}$ & $\begin{array}{c}\text { Monitorar o } \\
\text { terminal }\end{array}$ & $\begin{array}{c}\text { Mesas, cadeiras, } \\
\text { câmeras, monitores e } \\
\text { equipamentos } \\
\text { necessários }\end{array}$ & $\begin{array}{c}\text { Iluminação natural, } \\
\text { sistema de monitoramento }\end{array}$ \\
\hline Cabine de & $\begin{array}{c}\text { Anunciar chegada } \\
\text { e saída dos ônibus } \\
\text { e outras } \\
\text { informações }\end{array}$ & $\begin{array}{c}\text { Mesa, cadeira, } \\
\text { microfone, auto } \\
\text { falante, monitores }\end{array}$ & $\begin{array}{c}\text { Fácil acesso e visualização, } \\
\text { iluminação natural }\end{array}$ \\
& & \\
\hline
\end{tabular}

Fonte: O próprio autor.

\section{PRÉ DIMENSIONAMENTO}

A Tabela 03 apresenta o dimensionamento prévio das futuras áreas do terminal.

Tabela 03 - Dimensionamento prévio das áreas a serem construídas

\begin{tabular}{cc}
\hline & Área $\left(\mathrm{m}^{2}\right)$ \\
\hline Administração / Cabine de comunicação & 10 \\
Bilheterias & 100 \\
Comércios & 100 \\
Depósitos & 40 \\
Vestiário & 20 \\
Sanitários & 50 \\
Achados e perdidos / Guarda volumes & 10 \\
Juizado de menores & 10 \\
Guarda municipal/Polícia & 10 \\
Sala de espera & 150 \\
Restaurantes & 100 \\
Praça de alimentação & 100 \\
Telefonia & 5 \\
Circulação & 400 \\
Estacionamento & 250 \\
Baias de ônibus & 700 \\
TOTAL & 300 \\
\hline
\end{tabular}

Fonte: O próprio autor.

\section{FUNCIONOGRAMA}

A Figura 07 apresenta o diagrama do projeto a ser construído, levando em conta todos os elementos do mesmo. 


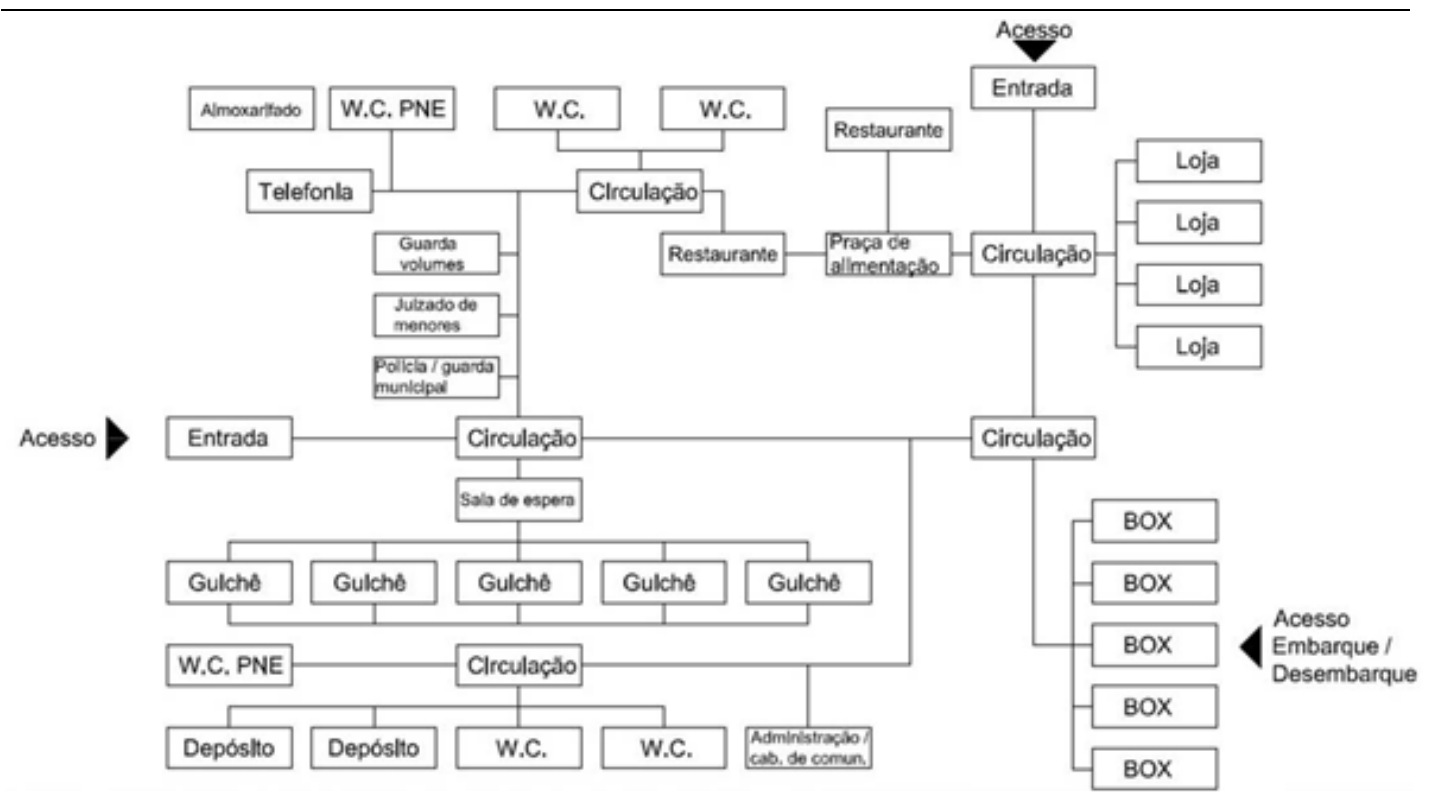

Figura 06 - Funcionograma do terminal Fonte: O próprio autor.

\section{CONCLUSÃO}

Parte da finalidade do terminal deveria ser atender a demanda dos usuários, proporcionando conforto e segurança enquanto aguarda e no momento do embarque/desembarque dos ônibus, características ausentes nesta atual configuração.

O objetivo da setorização dentro do terminal é a melhor organização e a separação dos ambientes cujo sua funcionalidade.

A partir dos resultados obtidos nesta monografia, realizar o projeto final do terminal rodoviário intermunicipal da cidade de Caçador - SC se torna muito menos complexo, a escolha da edificação juntamente com os parâmetros de uso e ocupação do solo obtidos na Lei de Zoneamento $n^{\circ} 168$, o estudo preliminar onde foi apresentado o levantamento de dados, o programa de necessidades e o funcionograma são peças fundamentais para chegar ao resultado final necessário. 


\section{REFERÊNCIAS}

AMARAL, Gilberto Luiz; AMARAL, Letícia Mary Fernandes; OLENIKE, João Eloi; STEINBRUCH, Fernando. Estudo sobre arrecadação de IPVA e sua proporcionalidade em relação à frota de veículos e à população brasileira. [S.I.], 2011.

DUNHAM, José Augusto. SIMTERP - Simulador para Terminais Rodoviários de Passageiros Intermunicipais: contribuição para a avaliação do desempenho de terminais rodoviários no estado do Rio de Janeiro. 2008. 167 f. Dissertação (Mestrado de Engenharia de Transportes) - Universidade Federal do Rio de Janeiro (UFRJ), Rio de Janeiro, RJ.

FERREIRA, Marcel; FANTIN, Bernadete Rossi Barbosa. Análise da viabilidade de mudança de local do terminal rodoviário de passageiros de Botucatu sob a ótica da acessibilidade. 2010. 16 f. Botucatu, SP.

GOOGLE, Maps. Disponível em: <https://www.google.com.br/maps/@26.7814315,-51.0076501,13z?hl=pt-BR>. Acesso em: 15 de mai. 2016.

PREFEITURA MUNICIPAL DE CAÇADOR - SC, Lei complementar $n^{\circ} 168$. Publicada em: 16 abr. 2010.

SIGSC, Sistema de Informações Geográficas - Governo de Santa Catarina.

Disponível em: <http://sigsc.sds.sc.gov.br/map/?public=true>. Acesso em: 15 de mai. 2016.

SOARES, Ubiratan Pereira. Procedimento para a localização de terminais rodoviários interurbanos, interestaduais e internacionais de passageiros. 2006. $343 \mathrm{f}$.

Dissertação (Mestrado em Engenharia de Transportes) - Universidade Federal do Rio de Janeiro (UFRJ), Rio de Janeiro, RJ. 